\title{
Discrimination Among Pre-School Children: Field Experimental Evidence
}

\author{
Annika J. List ${ }^{1}$, John A. List ${ }^{2}$, Anya Samek ${ }^{3}$
}

March 2017

\begin{abstract}
Social scientists for years have documented the pervasiveness of discrimination in product and labor markets. While the literature has recently attempted to measure the nature of such discrimination, much less work has been done exploring the origins of discrimination. We make a modest step in this direction by reporting data from a field experiment attempting to measure discrimination amongst 3-5 year olds. Using a design that isolates discriminatory behaviors in economic games, we find that both White and Hispanic children send more resources to Black children than White children, whereas black children send equal amounts. This provides a first glimpse that suggests preferences amongst the young do not show similar patterns as preferences of adults.
\end{abstract}

JEL Classifications: J7, C9

Keywords: discrimination, field experiment, children

\footnotetext{
${ }^{1}$ Becker Center on Chicago Price Theory, The University of Chicago, 5750 South Woodlawn Avenue, Chicago, IL 60637, USA

${ }^{2}$ Department of Economics, The University of Chicago, 5750 South Woodlawn Avenue, Chicago, IL 60637, USA

${ }^{3}$ CESR and Department of Economics, University of Southern California, 635 Downey Way, Los Angeles, CA 90037, USA
} 


\section{Introduction}

One would be hard-pressed to find a more divisive issue for modern economies than race and civil rights. One area of active research within economics is determining the magnitude and nature of discrimination. ${ }^{4}$ For example, List (2004) uses field experiments in a market for memorabilia to provide an empirical framework to disentangle the underlying forces behind differential market treatment. List (2004) finds a tendency for women, the elderly, and nonCaucasians to receive offers that are inferior to those received by majority agents, and that such behaviors are primarily driven by profit motives rather than a distaste for certain subgroups.

Such studies provide evidence of discrimination against minorities in markets, yet our understanding of where such preferences emanate remains speculative. We use a field experiment to explore how race impacts the choices made by children ages 3-5 in a sequence of dictator games. In each round, children were matched to teddy bears or other students and decided how many of their marshmallows to send them. We unobtrusively indicated the race of the match by showing pictures of hands (lighter or darker skin color) or pictures of teddy bear paws (light or dark brown).

One novelty of our design is that we use the teddy bears as a control in order to rule out that preferences are driven solely by dislike for darker or lighter colors. By comparing the aversion to giving to a darker color hand person relative to darker paw teddy bear, we disentangle the role of racial discrimination from preferences for colors in children's choices. While many dictator games with children use other children as the recipient, teddy bears are also developmentally appropriate for this age group, since they (and other inanimate objects) are commonly used as

\footnotetext{
${ }^{4}$ Within economics, the two major theories of discrimination are $i$ ) certain populations having a general "distaste" for minorities (Becker, 1957) or a general "social custom" of discrimination (Akerlof, 1980) and ii) statistical discrimination (see, e.g., Arrow 1972).
} 
recipients in similar resource allocation games in developmental psychology (e.g., see Chernyak et al., 2016).

We find that white and Hispanic children send more resources to black children than White children, whereas black children send equal amounts. This stands in an interesting contrast to the literature on discrimination (Riach and Rich, 2002; List, 2006), which reports broad discrimination against minorities. In related work, researchers find that adult giving is higher to in-group versus out-group peers (Fehr et al., 2008; Ben-Ner et al., 2009). Researchers also find that language discrimination in a bilingual city in Italy increases with the child's age (Angerer et al., 2016).

Our work is related to research on how people give resources to others. Results from the philanthropy literature suggest that minority fundraisers in a door-to-door campaign are less likely to obtain contributions and receive smaller gifts (List and Price, 2009). However, in another study, victims' race did not have an impact on willingness to donate to charity (Fong and Luttmer, 2009). We attempt to advance both of these strands of work with our field experiment.

If our dictator game measures discrimination in a manner the literature suggests, then our findings suggest that discriminatory preferences amongst the young do not show similar patterns as adults. This insight has important implications: school programs, and public approaches more generally, have an opportunity to stem the differential treatment observed in markets.

\section{Experimental Design}

Our experiment was conducted at the Griffin Early Childhood Center (GECC) in 2010. The GECC serves as a 'laboratory' for experiments of this sort (see, e.g., List and Samek, 2013, which uses similar data to explore the origins of charitable acts). Our 117 experimental subjects were ages 3.27-5.22 (M=4.30, S.D.=0.56). 
Children were taken out of the classroom to participate one-on-one with the experimenter. The experimenter read the script, including questions on understanding (see appendix), and took notes while the child made decisions. Participation took 10-15 minutes, and children were immediately rewarded at the end with a sticker. Children kept all of the marshmallows that they 'earned' during the experiment.

We designed dictator games in which children were matched with anonymous students or teddy bears from the other class. In each of 4 rounds, children selected how many marshmallows out of their allocated 5 to send to their match. The match was represented by a photo of the match's outstretched hand or paw. At the end of each game, all marshmallows the child allocated to herself were placed in her paper bag, and all marshmallows the child allocated to her match were placed in the paper bag for the match. Children were actually matched with another student from the other school, and these students received their marshmallows after the experiment was completed. The teddy bears did not receive resources.

Figure 1 displays the photos that were shown for each of the matches used in the experiment. The race of the match was disclosed by changing the color of the match's hand (child match) or paw (teddy bear). The gender of the match was not disclosed, and using 'he' or 'she' was avoided throughout the experiment, since children are sensitive to gender at this age. Pictures of hands and paws were used to assure that attractiveness of the match does not play a role and to avoid disclosing gender. 
Figure 1: Photos of the Matches

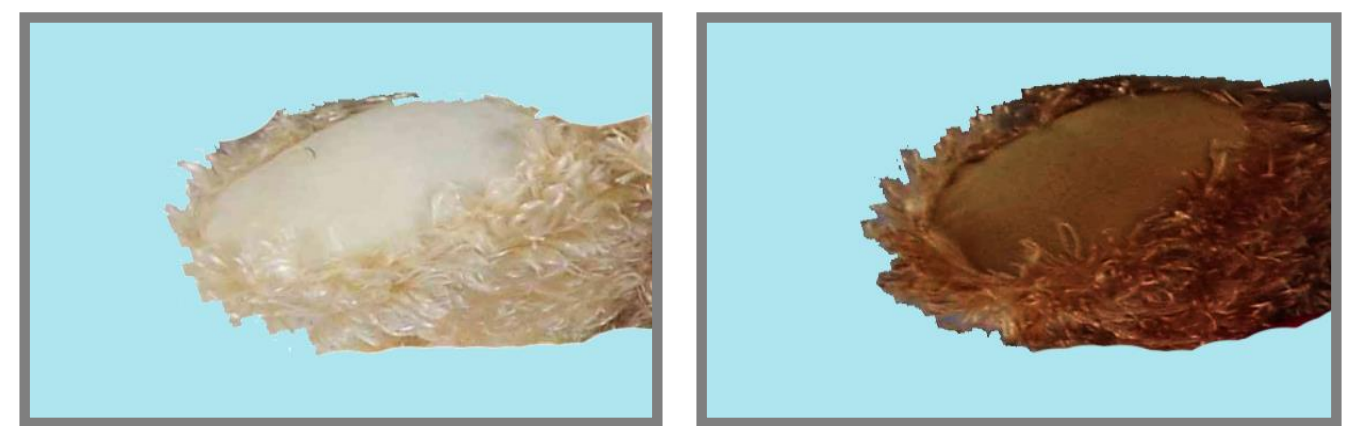

"Pat the Teddy Bear's" Paw

“Tap the Teddy Bear's” Paw
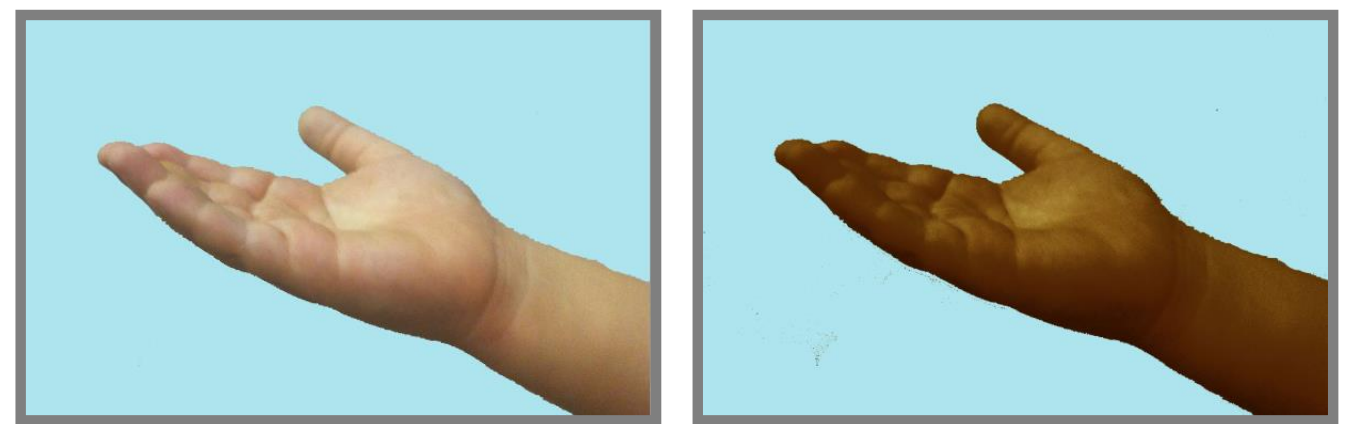

"Pat the Child's" Hand

“Tap the Child's" Hand

One difference between our experiment and the standard dictator game is that each marshmallow sent by the child to his/her match was passed through a box before going to the match. All children participated in one regular round, and one round where the box converted the marshmallows to cotton balls (children were told teddy bears like cotton balls). Each subject participated in 4 dictator tasks: 2 with black recipients and 2 with white recipients. We randomized subjects to either the student match or teddy match treatment for all dictator tasks.

\section{Results}

Figure 2 summarizes our results. On average, white children send 0.97 marshmallows to white recipients and 1.47 marshmallows to black recipients. Similarly, Hispanic children send 
1.18 marshmallows to white recipients and 1.55 marshmallows to black recipients. Alternatively, black children send more marshmallows to white recipients (1.33) relative to other blacks (0.99).

To test whether these differences are statistical at conventional levels, we pool the white and Hispanic data because in homogeneity tests we could not reject the null ( $p>0.66$ for all tests). Non-black children send significantly more resources to black recipients $(1.53$, s.e $=0.18)$ than to white recipients $(1.12$, s.e. $=0.18)$ (paired t-test $p$-value $=0.02)$. Black children send fewer resources to blacks than to white recipients; yet, this result is not significant at conventional levels (paired ttest $p$-value $=0.17$.

We conduct ordinary least squares regressions (see Table 1) including 4 decisions and clustering standard errors at the subject level, using the equation:

$$
\text { Giving }_{i}=\alpha+\beta B_{i}+\delta T_{i}+\eta Z_{i}+\lambda X_{i}+\varepsilon_{i}
$$

where $i$ is the participant indicator, Giving ${ }_{i}$ is the amount given to the recipient $(0-5), B_{i}$ is a dummy

for black recipient, $T_{i}$ is a dummy for teddy bear, $Z_{i}$ is a vector of other game-specific controls and $X_{i}$ is a vector of subject demographics. Next, we estimate a regression that includes interactions with child race (dummy for black) and dummies for black recipient and teddy bear treatment:

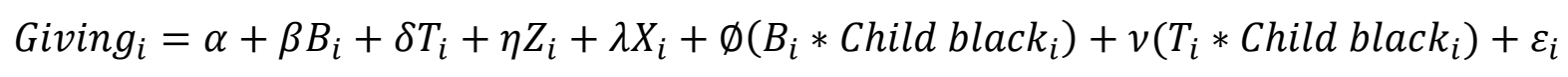

Figure 2: Giving to White/Black Recipients, by Child Race 


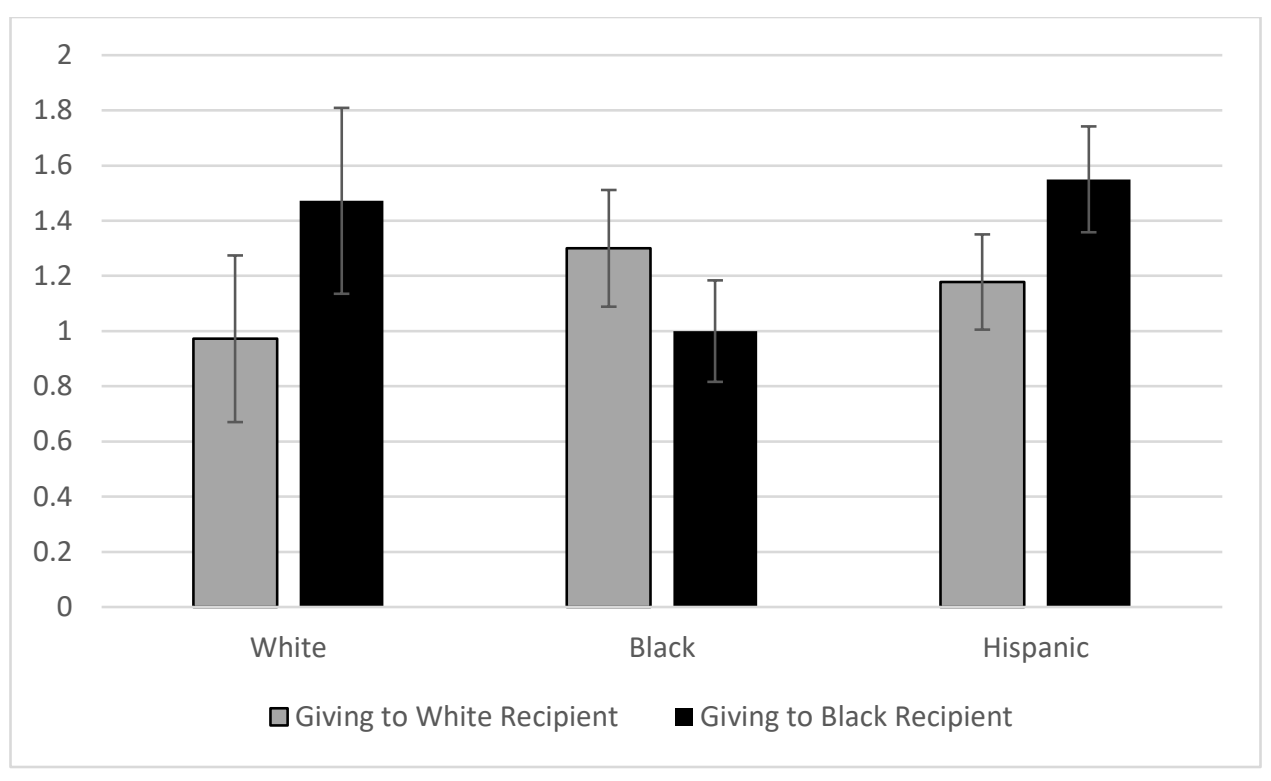

Table 1: Regression Results

\begin{tabular}{lcc}
\hline & $(1)$ & $(2)$ \\
& Giving & Giving \\
\hline Black recipient & 0.209 & $0.480^{* *}$ \\
& $(0.147)$ & $(0.204)$ \\
Teddy recipient & 0.224 & 0.244 \\
& $(0.249)$ & $(0.293)$ \\
Child age (years) & -0.0779 & -0.0771 \\
& $(0.224)$ & $(0.225)$ \\
Child is black & -0.154 & 0.214 \\
& $(0.238)$ & $(0.294)$ \\
Child is black * Black Recipient & & $-0.742 * *$ \\
& & $(0.299)$ \\
Child is black * Teddy recipient & & -0.0410 \\
& & $(0.298)$ \\
Additional experiment controls & YES & YES \\
& $(0.0693)$ & $(0.0689)$ \\
Constant & 0.970 & 0.850 \\
& $(0.988)$ & $(1.000)$ \\
Unique subjects & 117 & 117 \\
Observations & 459 & 459 \\
R-squared & 0.026 & 0.034 \\
\hline
\end{tabular}

Notes: Robust standard errors in parentheses. With 117 subjects and 4 decisions, we would expect 468 observations. However, 9 decisions include missing data, either because the experimenter failed to write it down or the subject chose not to respond to the question. $* * * \mathrm{p}<0.01, * * \mathrm{p}<0.05, * \mathrm{p}<0.1$

We see support for our unconditional analysis: while in the regression without interactions, we do not see impacts on giving by teddy or race of recipient, we do see significant effects when 
we include interaction terms. In specification (2), the coefficient on Black is positive and statistically significant $(p=0.02)$, while the coefficient on Black Child *Black Recipient is negative and statistically significant $(p=0.014)$. To account for multiple hypothesis testing (teddy/child recipient, black/white recipient and whether the child is black or white), we do a Bonferroni adjustment to the alpha level we are willing to accept as statistically significant $(0.05 / 3=0.017)$. Black Child * Black Recipient continues to be statistically significant at this level, while the coefficient on Black is now only marginally significant. Contrary to our expectation, we do not see a difference when comparing giving to teddy bears versus to human children.

These results join a small literature using dictator games to investigate discrimination among children. Related work shows Canadian white children tend to favor white children in the dictator game relative to minority recipients (Friesen et al., 2012), in contrast to our work showing non-black children favor black recipients. The authors found that minority recipients showed outgroup favoritism, similar to our result related to black children. Pica-Smith (2010) finds children in $\mathrm{K}-1^{\text {st }}$ and $4^{\text {th }}-5^{\text {th }}$ grades differ in perceptions of intergroup friendships. Younger children (relative to older children) and black children (relative to white children) held more positive perceptions of intergroup friendships.

\section{Conclusions}

We use a field experiment with children ages 3-5 to provide a glimpse of distributional preferences between self and other in dictator games. We find that white and Hispanic children send more resources to black recipients than white recipients, whereas black children send equal amounts. This insight is consistent with the notion that preferences amongst the young do not show similar patterns as preferences of adults. Of course, many interpretations of these data are 
possible. For example, our data patterns are consistent with cohort effects, the experiment captures a different element of behavior than we assume, or other interpretations.

One implication of our results is that discrimination can be changed since it is not due entirely to biological reactions. Coupled with results in the literature that suggest a bulk of discrimination is statistical rather than taste-based (see List, 2004), we should devote resources to improve education and human capital development rather than enforce laws aimed at combating animus.

\section{Acknowledgements}

This work was supported by the Kenneth and Anne Griffin Foundation. We thank the directors, principals and staff at the Griffin Early Childhood Center for being accommodating during the data collection. We thank Edie Dobrez and Phuong Ta for valuable research assistance. 


\section{References}

Akerlof, George A., "The Theory of Social Custom, of Which Unemployment may be One Consequence," Quarterly Journal of Economics, IXIV (1980), 749-775.

Angerer, Silvia, Daniela Glätzle-Rützler, Philipp Lergetporer, and Matthias Sutter. "Cooperation and discrimination within and across language borders: Evidence from children in a bilingual city." European Economic Review 90 (2016): 254-264.

Arrow, Kenneth. "The Theory of Discrimination," in Discrimination in Labor Markets, O. Ashenfelter and A. Rees, eds. (Princeton, NJ: Princeton University Press, 1972).

Becker, Gary, The Economics of Discrimination, 2nd ed., (University of Chicago Press, 1975).

Ben-Ner, Avner, et al. "Identity and in-group/out-group differentiation in work and giving behaviors: Experimental evidence." Journal of Economic Behavior \& Organization 72.1 (2009): 153-170.

Chernyak, Nadia, Beth Sandham, Paul L. Harris, and Sara Cordes. "Numerical cognition explains age-related changes in third-party fairness." Developmental psychology 52, no. 10 (2016): 1555.

Fehr, Ernst, Helen Bernhard, and Bettina Rockenbach. "Egalitarianism in young children." Nature 454.7208 (2008): 1079-1083.

Fong, Christina and Erzo Luttmer. "What Determines Giving to Hurricane Katrina Victims? Experimental Evidence on Racial Group Loyalty", American Economic Journal:

Applied Economics, 1(2), (2009): pp. 64-87.

Friesen, Jane, et al. "Ethnic identity and discrimination among children." Journal of Economic Psychology 33.6 (2012): 1156-1169.

List, John A., "The Nature and Extent of Discrimination in the Marketplace: Evidence from the Field," Quarterly Journal of Economics, (2004), 119(1), pp. 49-89.

List, John A. "Field Experiments: A Bridge between Lab and Naturally Occurring Data," The B.E. Journal of Economic Analysis \& Policy, (2006), 6(2 - Advances), Article 8.

List, John A. and Michael K. Price, "The Role of Social Connections in Charitable Fundraising: Evidence from a Natural Field Experiment," Journal of Economic Behavior and Organization, (2009), 69(2), pp. 160-169.

List, John A.; and Samak, Anya C, "Exploring the origins of charitable acts: Evidence from an artefactual field experiment with young children," Economics Letters, (2013), 118(3), pp. 431-34.

Pica-Smith, Cinzia. "Children's perceptions of interethnic and interracial friendships in a multiethnic school context." Journal of Research in Childhood Education 25.2 (2011): 119-132. 
Riach, Peter A., and Judy Rich, "Field Experiments of Discrimination in the Market Place," Economic Journal, CXII (2002), F480-F518.

\section{Appendix - Experimental Instructions}

\section{INTRODUCTION}

Thank you for playing with me today. Today we are going to play with different boxes and marshmallows -

\section{* GREEN BOX INTRO}

Now I'm going to tell you about this box. This is the Green Box. Do you want to see what it does? It doesn't change marshmallows into anything. You can give me a marshmallow to send through the box, and it will come out on this side as a marshmallow. Let's put a marshmallow through here - there, it came out a marshmallow.

(1) Do you remember, if you put a marshmallow through the Green Box, what comes out? (Yes/No, a marshmallow comes out. Watch let's do it again... Yep, a marshmallow came out)

\section{* BASE_REG}

Now we are going to play with the Green Box. I am going to put marshmallows in the middle, and you are going to decide how many marshmallows to keep and how many to send through the Green Box. Any marshmallows you send through the Green Box are going to go in this trash, and nobody gets it. Any marshmallows you keep we will put in your bag here to take home.

- When you send a marshmallow through the Green Box, what comes out? (Yes/No, a marshmallow comes out)

- Where does the marshmallow you send through the Green Box go? (Yes/No, it goes in the trash and nobody gets it).

If you want to send a marshmallow through the box, you put it in the basket like this. If you want to keep a marshmallow, you put it on your plate.

- If you want to send a marshmallow, where do you put it? (Yes/No, you put it in this basket here and I put it through the box).

- If you want to keep a marshmallow, where do you put it? (Yes/No, you keep the marshmallows you put on this plate).

Okay, here are the marshmallows. You decide how many to keep and how many to send. The ones you keep you put on your plate. The ones you send you put in this basket. (put out the 5 marshmallows; prompt if child doesn't do task).

[END] Okay, these marshmallows go in the trash and nobody gets them, and these marshmallows go in your bag.

Let's play again.

* REG WHITE

Now we are going to play with the Green Box. I'll tell you about a child from the other school, we'll call the child Pat. Pat didn't get to play this game today. Pat likes to eat marshmallows like this one (show marshmallow). This means that any marshmallow you send to Pat, Pat will eat it. Here is a picture of Pat's hand. 
- What will Pat do with a marshmallow like this one? (Yes/No, Pat will eat it)

I'm going to put marshmallows in the middle, and you decide how many to keep and how many to send to Pat.

If you want to send marshmallows to Pat, you put them in this basket and I will put the basket through the Green Box. The marshmallows will go on Pat's plate. If you want to keep marshmallows, you put them on your plate here.

- When you send a marshmallow through the Green Box, what comes out? (Yes/No, a marshmallow comes out)

- If you want to send a marshmallow, where do you put it? (Yes/No, you put it in this basket here and we put it through the box).

- If you want to keep a marshmallow, where do you put it? (Yes/No, you keep the marshmallows you put on this plate).

[END] Okay, these marshmallows are for Pat so we will put in this bag to send Pat, and these marshmallows go in your bag to take home.

Let's play again.

\section{* REG BLACK}

Now we are going to play with the Green Box. I'll tell you about another child from the other school, we'll call the child Tap. Tap didn't get to play this game today. Tap likes to eat marshmallows like this one (show marshmallow). This means that any marshmallow you give to Tap, Tap will eat it. Here is a picture of Tap's hand.

- What will Tap do with a marshmallow like this one? (Yes/No, Tap will eat it)

I'm going to put marshmallows in the middle, and you decide how many to keep and how many to send to Tap.

If you want to send marshmallows to Tap, you put them in this basket and I will put the basket through the Green Box. The marshmallows will go on Tap's plate. If you want to keep marshmallows, you put them on your plate here.

- When you send a marshmallow through the Green Box, what comes out? (Yes/No, a marshmallow comes out)

- If you want to send a marshmallow, where do you put it? (Yes/No, you put it in this basket here and we put it through the box).

- If you want to keep a marshmallow, where do you put it? (Yes/No, you keep the marshmallows you put on this plate).

[END] Okay, these marshmallows are for Tap so we will put in this bag to send Tap, and these marshmallows go in your bag to take home.

Let's play again.

\section{* RED BOX INTRO}

Next I'm going to tell you about this box. This is the Red Box. Do you want to see what it does? It changes marshmallows into cotton balls. You can give me a marshmallow to send through the box, and it will come out on this side as a cotton ball. Let's put a marshmallow through here - there, it came out a cotton ball.

(1) If you put a marshmallow through the Red Box, what comes out? (Yes/No, a cotton ball comes out. Watch let's do it again... Yep, a cotton ball came out).

\section{MAGIC WHITE}


Now we are going to play with the Red Box. I'll tell you about a child from the other school, we'll call the child Pat. Pat didn't get to play this game today. Pat likes to eat marshmallows like this one (show marshmallow), but Pat can't eat cotton balls like this one. This means that any cotton ball you give to Pat, Pat can't eat it and Pat will have to throw it away. Here is a picture of Pat's hand.

- What will Pat do with a cotton ball like this one? (Yes/No, Pat will throw it away because Pat can't eat it)

I'm going to put marshmallows in the middle, and you decide how many to keep and how many to send to Pat.

If you want to send marshmallows to Pat, you put them in this basket and I will put the basket through the Red Box. The marshmallows will turn into cotton balls and will go on Pat's plate. If you want to keep marshmallows, you put them on your plate here.

- When you send a marshmallow through the Red Box, what comes out? (Yes/No, a cotton ball comes out)

- If you want to send a marshmallow, where do you put it? (Yes/No, you put it in this basket here and we put it through the box).

- If you want to keep a marshmallow, where do you put it? (Yes/No, you keep the marshmallows you put on this plate).

[END] Okay, these cotton balls are for Pat so we will put in this bag to send Pat, and these marshmallows go in your bag to take home.

Let's play again.

\section{* MAGIC BLACK}

Now we are going to play with the Red Box. I'll tell you about a child from the other school, we'll call the child Tap. Tap didn't get to play this game today. Tap likes to eat marshmallows like this one (show marshmallow), but Tap can't eat cotton balls like this one. This means that any cotton ball you give to Tap, Tap can't eat it and Tap will have to throw it away. Here is a picture of Tap's hand.

- What will Tap do with a cotton ball like this one? (Yes/No, Tap will throw it away because Tap can't eat it)

I'm going to put marshmallows in the middle, and you decide how many to keep and how many to send to Tap. At the end, we will send Tap what you decided to give to Tap.

If you want to send marshmallows to Tap, you put them in this basket and I will put the basket through the Red Box. The marshmallows will turn into cotton balls and will go on Tap's plate. If you want to keep marshmallows, you put them on your plate here.

- When you send a marshmallow through the Red Box, what comes out? (Yes/No, a cotton ball comes out)

- If you want to send a marshmallow, where do you put it? (Yes/No, you put it in this basket here and we put it through the box).

- If you want to keep a marshmallow, where do you put it? (Yes/No, you keep the marshmallows you put on this plate).

[END] Okay, these cotton balls are for Tap so we will put in this bag to send Tap, and these marshmallows go in your bag to take home.

\section{* FINISH}

We are done! Good job. You get a sticker. You can eat some of your marshmallows now and we will put the rest in this bag to take home at the end of today. 